\title{
O CASO RAPOSA SERRA DO SOL NO SUPREMO TRIBUNAL FEDERAL: \\ UMA ANÁLISE A PARTIR DO PROCEDIMENTALISMO DEMOCRÁTICO DE HABERMAS E NINO
}

\author{
THE CASE “RAPOSA SERRA DO SOL” IN BRAZILIAN FEDERAL SUPREME COURT: \\ AN ANALYSIS REGARDING HABERMAS' AND NINO'S DEMOCRATIC PROCEDURALISM
}

\begin{abstract}
Milena Petters Melo
Professora Titular de Direito Constitucional e Direitos Humanos da Universidade Regional de Blumenau (FURB).

Coordenadora do Núcleo de Estudos em Constitucionalismo, Internacionalização e Cooperação (Constinter-Furb).

Coordenadora para a área lusófona do Centro Euroamericano Sulle Politiche Costituzionali (Cedeuam, Itália-Brasil). Professora da Academia Brasileira de Direito Constitucional (ABDConst). Professora convidada do Doutorado em Diritto Comparato e Processi di Integrazione da Università degli Studi della Campania Luigi Vanvitelli, Italia. Doutora em Direito pela Università del Salento, Italia. mpettersmelo@gmail.com

Thiago Burckhart Doutorando em Diritto Comparato e Processi di Integrazione pela Università degli Studi della Campania Luigi Vanvitelli, Itália. Mestre em Direito pela Universidade Federal de Santa Catarina (2019). Pesquisador do Centro Euroamericano Sulle Politiche Costituzionali (Cedeuam, Itália-Brasil). Pesquisador do Núcleo de Estudos em Constitucionalismo, Internacionalização e Cooperação (Constinter-Furb). thiago.burckhart@outlook.com
\end{abstract}

Resumo: Desde a promulgação da Constituição de 1988 houve um exponencial aumento de casos judicializados no âmbito do controle de constitucionalidade relativos aos direitos de povos indígenas. O caso Raposa Serra do Sol (PET 3.388/RR), julgado em 2009 pelo STF, pode ser considerado o de maior repercussão jurídica. Neste caso, o STF atuou como legislador ativo ao criar 19 salvaguardas institucionais, além da tese do "marco temporal", que passaram a ser utilizadas noutros casos como argumento jurídico para restringir direitos de povos indígenas, não obstante a contestação por parte de juristas, antropólogos e instituições indigenistas. Desse modo, nascem interrogativos sobre os limites da atuação da Suprema Corte no âmbito do controle de constitucionalidade, sobretudo no que diz respeito à sua legitimidade no caso em questão. A análise insere-se no campo da teoria constitucional e da teoria política, sendo realizada com base nas teorias do procedimentalismo democrático de Jürgen Habermas e Carlos Santiago Nino.

Palavras-chave: Raposa Serra do Sol. Supremo Tribunal Federal. Procedimentalismo democrático. Habermas. Nino.

Abstract: After the promulgation of the 1988 Brazilian Constitution, there has been an exponential increase in judicialized cases under the control of constitutionality regarding to the rights of indigenous peoples. The Raposa Serra do Sol's case (PET 3.388 / RR), decided in 2009 by the Supreme Court, may be considered the one with greatest legal repercussion. In this case, the Supreme Court acted as an active legislator by creating 19 institutional safeguards, in addition to the "marco temporal" thesis, which have been used in other cases as a legal argument to restrict rights of indigenous peoples, notwithstanding the contestation of jurists, anthropologists and indigenous institutions. Therefore, questions arise on the limits of the Supreme Court's role in the control of constitutionality, especially regarding its legitimacy in this case. The analysis is grounded into the field of constitutional theory and political theory, based on the theories of democratic proceduralism by Jürgen Habermas and Carlos Santiago Nino.

Key words: Raposa Serra do Sol. Brazilian Supreme Court. Democratic procedurlism. Habermas. Nino.

\section{Para citar este artigo}

ABNT NBR 6023:2018

MELO, Milena Petters; BURCKHART, Thiago. O caso Raposa Serra do Sol no Supremo Tribunal Federal: uma análise a partir do procedimentalismo democrático de Habermas e Nino. Prisma Jurídico, São Paulo, v. 19, n. 1, p. 119-137, jan./jun. 2020. http://doi.org/10.5585/prismaj.v19n1.12350. 


\section{Introdução}

A Constituição de 1988 realizou um amplo e detalhado processo de constitucionalização dos direitos de povos indígenas no Brasil - muito embora tenha havido proteção constitucional aos direitos territoriais de povos indígenas desde o texto constitucional de 1934. Em paralelo ao processo de afirmação destes direitos no país, ocorreu também um aumento exponente dos casos que passaram a ser judicializados nas mais diferentes instâncias da justiça Estadual e Federal em todo o território nacional. Neste contexto, o Supremo Tribunal Federal (STF) passou a ser chamado por diversas vezes para decidir causas que tiveram por objeto os direitos de povos indígenas, sobretudo no que se refere aos seus "direitos territoriais", que ainda marca a "questão indígena" no país.

Dentre os casos, a Petição 3.388/RR (PET 3.388/RR), popularmente conhecida como caso Raposa Serra do Sol tornou-se um leading case em razão da sua repercussão tanto no campo social e midiático, quanto no âmbito político e jurídico. Resultado de um conflito agrário no Estado de Roraima, cujo processo administrativo demarcatório durou mais de 32 anos, o Supremo Tribunal Federal reconheceu o direito originário à terra dos povos que habitam a Terra Indígena daquela região. No entanto, criou 19 condicionantes - as 19 salvaguardas institucionais - além da polêmica tese do "marco temporal" - que interpreta restritivamente o direito à posse dos povos indígenas às suas terras - e que foram aplicadas posteriormente em outros casos pela Segunda Turma do STF e por juízes de primeiro e segundo grau em todo o território nacional - não obstante a contestação por parte de juristas, povos indígenas, Ministério Público Federal e organizações indigenistas.

O caso em questão, portanto, embora tenha sido decidido há dez anos, coloca em evidência uma problemática ainda atual, relativa aos limites da jurisdição constitucional, sobretudo nos casos que envolvem minorias étnicas - como é o caso dos povos indígenas - que são subrepresentados no Parlamento Nacional. Isso porque trata-se de um caso que claramente demonstra a atuação da Suprema Corte como legislador ativo, no qual os Ministros criaram interpretações que faticamente limitam a aplicação do texto constitucional para os povos indígenas. Nesse contexto, nasce o questionamento que guia a reflexão proposta neste trabalho: pode ser considerada legítima a atuação do Supremo Tribunal Federal no caso Raposa Serra do Sol? Para responder a esta pergunta, toma-se como aporte teórico as teorias do procedimentalismo democrático de Jürgen Habermas e de Carlos Nino, entendidas como propostas alternativas ao processo cada vez mais característico do cenário político brasileiro de agigantamento do Poder Judiciário, da jurisdição constitucional e do papel dos juízes. Estes 
autores propõem uma teoria do controle de constitucionalidade limitada e procedimental que esteja em consonância com a teoria democrática.

Nesse sentido, o objetivo deste artigo é realizar uma análise crítica da atuação do Supremo Tribunal Federal no caso Raposa Serra do Sol a partir do procedimentalismo democrático de Jürgen Habermas e Carlos Santiago Nino. O trabalho insere-se, portanto, no âmbito da teoria e filosofia constitucional com aportes da teoria política, sendo dividido em três partes: I - O caso Raposa Serra do Sol no Supremo Tribunal Federal; II - As teorias do procedimentalismo democrático de Jürgen Habermas e Carlos Nino; III - Uma análise crítica da atuação do Supremo Tribunal Federal. Como conclusão, com base no aporte teórico, tem-se que a atuação do STF foi ilegítima, de modo que se evidencia a necessidade de estabelecer parâmetros constitucionais e democráticos para a atuação da Corte.

\section{O caso Raposa Serra do Sol e o Supremo Tribunal Federal}

No dia 19 de março de 2009, o Tribunal Pleno do Supremo Tribunal Federal proferiu decisão em sede da Petição n. 3.388/RR, popularmente conhecido como "caso Raposa Serra do Sol” (STF, 2019). Em meio às reivindicações de povos indígenas, instituições indigenistas e representantes do agronegócio, e após três pedidos de vista que adiaram o julgamento de 2008 para 2009, a sentença pôs fim a um conflito político que datava, naquele tempo, 32 anos - a contar da instauração do primeiro grupo de trabalho para início do procedimento administrativo demarcatório.

A referida Petição, uma ação popular impetrada em 2005 pelo Senador à época Augusto Afonso Botelho Neto (PT/RR) em face da União - logo após a terra indígena ter sido homologada e formalmente registrada - contestava e requeria a impugnação do modelo de demarcação contínua da Terra Indígena Raposa Serra do Sol, requerendo ainda a suspensão liminar dos efeitos da Portaria n. 534/2005 e do decreto homologatório assinado pelo então Presidente da República Luiz Inácio Lula da Silva, com o objetivo de declarar sua nulidade. Esta ação popular alastrou as discussões políticas e jurídicas relativas à demarcação da terra indígena no âmbito judiciário.

Desde o início dos trabalhos de demarcação, uma promessa histórica dos representantes políticos federais, houve profundos e graves conflitos interétnicos, sobretudo a partir da intensificação dos trabalhos demarcatórios ocorridos a partir da década de $1990^{1}$. De um lado,

\footnotetext{
${ }^{1}$ Para compreender o processo administrativo de demarcação da Terra Indígena Raposa Serra do Sol, ver: Mota (2009, pp. 73125).
} 
os cinco povos indígenas habitantes da referida Terra - os Makuxi, Ingarikó, Wapixana, Taurepang e Patamona, que somam uma população de aproximadamente 20.000 indígenas -, reivindicavam seu direito, reconhecido pelo art. 231 da Constituição Federal e incisos, relativo à obrigação do Estado de reconhecer e demarcar suas terras. Por outro, extrativistas, fazendeiros e garimpeiros pugnavam, em sentido contrário, pelo reconhecimento de seus direitos territoriais sobre aquela área² .

Esta Petição alastrou as discussões jurídico-políticas referentes à demarcação desta terra indígena no âmbito judiciário logo após a conclusão de seu processo demarcatório. Ao longo do processo administrativo a Justiça Federal e o Supremo Tribunal Federal foram, por diversas vezes, instados a se manifestar ou decidir sobre aspectos jurídicos que circunscreviam o caso ${ }^{3}$, de modo que a judicialização tornou-se frequente em razão da complexidade dos conflitos subjacentes ao caso. Em razão de ser contestada historicamente pelos empresários ruralistas e extrativistas da região, a PET 3.388/RR converteu-se em símbolo tanto das reivindicações de povos indígenas quanto daquelas dos ruralistas da região ${ }^{4}$.

O processo de julgamento do caso pelo Supremo Tribunal Federal iniciou-se em 27.08.2008. O relator do caso, ministro Ayres Britto proferiu seu voto, tendo julgado improcedente a ação popular, fazendo assentar a condição de indígena à terra Raposa/Serra do Sol em tua totalidade e de forma contínua. Em seu voto, o ministro inovou ao estabelecer os marcos regulatórios relativos ao processo de demarcação das terras indígenas, quais sejam, 1) marco temporal de ocupação; 2) marco da tradicionalidade da ocupação; 3) marco da concreta abrangência fundiária e da finalidade prática da ocupação tradicional; e 4) marco do conceito fundiariamente extensivo do chamado "princípio da proporcionalidade" (STF, 2019, p. 295 308).

A tese do "marco temporal de ocupação", também conhecido como "marco temporal" é, dentre os marcos acima citados, a que mais gerou repercussão política e jurídica. Ela afirma que os povos indígenas só possuem direito às terras que nelas se encontravam na data da promulgação da Constituição de 1988 - com a exceção de comprovado esbulho renitente. Tratase de uma interpretação restritiva aos direitos territoriais de povos indígenas presentes na

\footnotetext{
${ }^{2}$ O conflito na Terra Indígena intensificou-se sobretudo a partir da década de 1970, com a invasão dos garimpeiros na área indígena e a fundação por eles de povoados. Na década de 1990, a construção de rodovias no interior da área indígena e a proposta da construção de uma usina hidrelétrica aprofundaram os conflitos entre os povos indígenas e as autoridades locais. Para aprofundamentos, ver Kayser (2010, p. 385).

${ }^{3}$ Nas palavras de Luiz Fernando Villares, "a judicialização do processo de demarcação, paradoxalmente, é um fenômeno que acompanha a conquista dos direitos indígenas" [...] "Quase todo o processo de identificação e demarcação de terras indígenas que se inicia é acompanhado inexoravelmente por vários processos judiciais". (VILLARES, 2009, p. 145).

${ }^{4}$ Sobre os processos reivindicativos das terras indígenas Raposa Serra do Sol, ver: Ab'Sáber (2009); Yamada; Villares (2010, pp. 143-159).
} 
Constituição de 1988, além de representar uma ruptura com a "teoria do indigenato" (CUNHA, 1987; JÚNIOR, 1912), que historicamente reconheceu o direito originário dos povos indígenas às suas terras e tem sido aplicada desde a constituição do "direito indigenista" brasileiro.

Logo após o relator proferir seu voto, o ministro Menezes Direito pediu vistas do processo. O julgamento foi retomado em dezembro de 2008, com o oferecimento do voto parcialmente divergente do ministro Menezes Direito. Nas palavras de Erica Magami Yamada e Luis Fernando Villares, "ciente de que um voto contrário à demarcação contínua da Terra Indígena não seria bem recebido pela maioria do Plenário, o que o colocaria numa posição desconfortável, esse ministro estabeleceu 19 condicionantes - ou ressalvas - às demarcações”. Essas 19 ressalvas somam-se aos quatro marcos estabelecidos no voto do relator como um conjunto de medidas a serem observadas no decorrer do processo administrativo demarcatório para a caracterização ou não de uma terra como indígena.

Seguidamente ao voto do ministro Menezes Dias, passaram a votar favoravelmente à constitucionalidade da demarcação da terra indígena em questão os ministros Carmen Lúcia, Ricardo Lewandowski, Eros Grau, Joaquim Barbosa e Cezar Peluso. Houve um novo pedido de vistas pelo ministro Marco Aurélio. O julgamento da ação retornou no dia 18.04.2009, na qual o ministro Marco Aurélio proferiu seu voto divergente, pela inconstitucionalidade da demarcação da terra. Nesta data o ministro Cesar de Mello proferiu seu voto favorável à demarcação, e em razão do interrompimento da sessão, o ministro Gilmar Mendes, até então Presidente do Supremo Tribunal Federal, proferiu seu voto acompanhando o relator com o acréscimo das ressalvas realizadas pelos ministros Ayres Britto e Menezes Direito.

A ação foi, portanto, julgada parcialmente procedente, tendo sido vencidos os ministros Joaquim Barbosa e Marco Aurélio, o primeiro por julgá-la totalmente improcedente - inclusive no que se referem às ressalvas e marco temporal -, e o segundo por julgá-la totalmente procedente. Foi “declarada, então, a constitucionalidade da demarcação contínua da Terra Indígena Raposa Serra do Sol e afirmada a constitucionalidade do procedimento administrativo-demarcatório" (STF, 2009, p. 241). A constitucionalidade foi condicionada às salvaguardas institucionais majoritariamente aprovadas pelo Plenário. Referidas salvaguardas ${ }^{5}$

\footnotetext{
${ }^{5}$ Salvaguaradas: "(I) o usufruto das riquezas do solo, dos rios e dos lagos existentes nas terras indígenas (art. 231, § $2^{\circ}$, da Constituição Federal) pode ser relativizado sempre que houver, como dispõe o art. $231, \S 6^{\circ}$, da Constituição, relevante interesse público da União, na forma de lei complementar; (II) o usufruto dos índios não abrange o aproveitamento de recursos hídricos e potenciais energéticos, que dependerá sempre de autorização do Congresso Nacional; (III) o usufruto dos índios não abrange a pesquisa e lavra das riquezas minerais, que dependerá sempre de autorização do Congresso Nacional, assegurando-se-lhes a participação nos resultados da lavra, na forma da lei; (IV) o usufruto dos índios não abrange a garimpagem nem a faiscação, devendo, se for o caso, ser obtida a permissão de lavra garimpeira; (V) o usufruto dos índios não se sobrepõe ao interesse da política de defesa nacional; a instalação de bases, unidades e postos militares e demais intervenções militares, a expansão estratégica da malha viária, a exploração de alternativas energéticas de cunho estratégico e o resguardo das riquezas de cunho estratégico, a critério dos órgãos competentes (Ministério da Defesa e Conselho de
} 
e marcos regulatórios foram justificados no acórdão pela "superlativa importância históricocultural da causa". No voto de Menezes Direito, constata-se a clara intensão de tornar o presente caso um paradigma que sirva de baliza para os futuros processos que envolvam a demarcação de terras indígenas que cheguem à apreciação do Supremo Tribunal Federal:

A partir da apreciação deste caso pude perceber que os argumentos deduzidos pelas partes são também extensíveis e aplicáveis a outros conflitos que envolvam terras indígenas. A decisão adotada neste caso certamente vai consolidar o entendimento da Suprema Corte sobre o procedimento demarcatório com repercussão também para o futuro. Daí a necessidade do dispositivo explicitar a natureza do usufruto constitucional e seu alcance (STF, 2019, p. 415-416).

Nesse sentido, embora a Suprema Corte tenha solucionado o caso Raposa Serra do Sol, reconhecendo a constitucionalidade da demarcação da terra indígena, é fato que as repercussões jurídicas e políticas do acórdão não se restringiram ao caso analisado. A decisão gerou mobilização política e contestação jurídica no que se refere à constitucionalidade das referidas salvaguardas e da tese do marco temporal. Para diversos especialistas e instituições indigenistas existem inconstitucionalidades em determinados pontos das salvaguardas bem como do marco temporal, o que gera insegurança jurídica para grande parte dos povos indígenas que ainda reivindicam o procedimento de reconhecimento e demarcação de suas terras.

De acordo com Luis Fernando Villares e Erica Magami Yamada (2010, p. 147) as salvaguardas podem ser descritas da seguinte forma: "algumas são interpretações ou repetições

Defesa Nacional), serão implementados independentemente de consulta às comunidades indígenas envolvidas ou à FUNAI; (VI) a atuação das Forças Armadas e da Polícia Federal na área indígena, no âmbito de suas atribuições, fica assegurada e se dará independentemente de consulta às comunidades indígenas envolvidas ou à FUNAI; (VII) o usufruto dos índios não impede a instalação, pela União Federal, de equipamentos públicos, redes de comunicação, estradas e vias de transporte, além das construções necessárias à prestação de serviços públicos pela União, especialmente os de saúde e educação; (VIII) o usufruto dos índios na área afetada por unidades de conservação fica sob a responsabilidade do Instituto Chico Mendes de Conservação da Biodiversidade; (IX) o Instituto Chico Mendes de Conservação da Biodiversidade responderá pela administração da área da unidade de conservação também afetada pela terra indígena com a participação das comunidades indígenas, que deverão ser ouvidas, levando-se em conta os usos, tradições e costumes dos indígenas, podendo para tanto contar com a consultoria da FUNAI; (X) o trânsito de visitantes e pesquisadores não índios deve ser admitido na área afetada à unidade de conservação nos horários e condições estipulados pelo Instituto Chico Mendes de Conservação da Biodiversidade; (XI) devem ser admitidos o ingresso, o trânsito e a permanência de não-índios no restante da área da terra indígena, observadas as condições estabelecidas pela FUNAI; (XII) o ingresso, o trânsito e a permanência de não índios não pode ser objeto de cobrança de quaisquer tarifas ou quantias de qualquer natureza por parte das comunidades indígenas; (XIII) a cobrança de tarifas ou quantias de qualquer natureza também não poderá incidir ou ser exigida em troca da utilização das estradas, equipamentos públicos, linhas de transmissão de energia ou de quaisquer outros equipamentos e instalações colocadas a serviço do público, tenham sido excluídos expressamente da homologação, ou não; (XIV) as terras indígenas não poderão ser objeto de arrendamento ou de qualquer ato ou negócio jurídico que restrinja o pleno exercício do usufruto e da posse direta pela comunidade indígena ou pelos índios (art. 231, $\S 2^{\circ}$, Constituição Federal, c/c art. 18, caput, Lei $\mathrm{n}^{\circ}$ 6.001/1973); (XV) é vedada, nas terras indígenas, a qualquer pessoa estranha aos grupos tribais ou comunidades indígenas, a prática de caça, pesca ou coleta de frutos, assim como de atividade agropecuária ou extrativa (art. $231, \S 2^{\circ}$, Constituição Federal, c/c art. 18, $\S 1^{\circ}$, Lei $\mathrm{n}^{\circ} 6.001 / 1973$ ); (XVI) as terras sob ocupação e posse dos grupos e das comunidades indígenas, o usufruto exclusivo das riquezas naturais e das utilidades existentes nas terras ocupadas, observado o disposto nos arts. 49 , XVI, e 231, $\S 3^{\circ}$, da CR/88, bem como a renda indígena (art. 43 da Lei $n^{\circ} 6.001 / 1973$ ), gozam de plena imunidade tributária, não cabendo a cobrança de quaisquer impostos, taxas ou contribuições sobre uns ou outros; (XVII) é vedada a ampliação da terra indígena já demarcada; (XVIII) os direitos dos índios relacionados às suas terras são imprescritíveis e estas são inalienáveis e indisponíveis (art. 231, $\S 4^{\circ}, \mathrm{CR} / 88$ ); e (XIX) é assegurada a participação dos entes federados no procedimento administrativo de demarcação das terras indígenas, encravadas em seus territórios, observada a fase em que se encontrar o procedimento (STF, 2019, p. 416-418). 
do texto constitucional e legal (as de número 1, 2, 3, 4, 14, 15, 16, 18), outras, comandos contrários aos já estabelecidos na convenção 169 da Organização Internacional do Trabalho (OIT), (5, 6, 7)", além disso, há “a criação de enunciados normativos pelas ressalvas 11, 12, 13, 17, e 19"6. Da mesma forma, o marco temporal é questionado por não haver qualquer critério jurídico, seja do ponto de vista constitucional, internacional ou mesmo infraconstitucional, que lhe dê sustentação (Cfe. CUNHA e BARSOSA, 2018). Apesar de ter sido definido, em resposta aos embargos de declaração impetrados pelo Ministério Público Federal logo após o proferimento do acórdão, que a aplicação do marco temporal e das salvaguardas se restringiriam ao caso Raposa Serra do Sol, a segunda turma do Supremo Tribunal Federal, presidida pelo ministro Gilmar Mendes, aplicou a tese do marco temporal em três decisões posteriores ${ }^{7}$, contrastando inclusive com a jurisprudência da primeira turma.

Além disso, a decisão também abriu o caminho para a aplicação do marco temporal e das salvaguardas por juízes federais e estaduais em causas envolvendo a demarcação de terras indígenas em todo o território nacional. Três pareceres da Advocacia-Geral da União também foram expedidos com o intuito de obrigar a Administração Pública Federal a "dar efetivo cumprimento, em todos os processos de demarcação de terras indígenas às condições fixadas na decisão do Supremo Tribunal Federal na PET 3.388/RR”. O último Parecer, ainda vigente, datado de 19 de julho de 2017, justifica a medida com o argumento de que as salvaguardas "tem sido reafirmada em diversos outros julgamentos do próprio Supremo Tribunal Federal, tornando indubitável a consolidação e estabilização normativa das salvaguardas institucionais" (AGU, 2017).

Em efeito, a resolução das questões jurídicas envolvendo direitos territoriais de povos indígenas pela Corte Suprema não teve na decisão do caso Raposa Serra do Sol uma efetiva solução - muito embora o acórdão tenha solucionado os conflitos indígenas relativos àquela terra especificamente -, mas foi o estopim de um novo debate político e jurídico, sobretudo em razão da atuação do Supremo Tribunal Federal como legislador ativo no caso em questão, com a introdução da tese do marco temporal e das 19 salvaguardas.

\section{Teorias do procedimentalismo democrático: Jürgen Habermas e Carlos Nino}

As teorias do procedimentalismo democrático de Jürgen Habermas (1997) e Carlos

\footnotetext{
${ }^{6}$ Para uma crítica às salvaguardas, ver: Miras (2009) e Kayser (2010).

${ }^{7}$ Um exemplo é a aplicação da tese do marco temporal (item 17) em pelo menos três decisões da segunda turma, cfe. RMS n. 29.087/DF; ARE 803.462/MS; e RMS 29.542/DF.
} 
Nino (1997) compartilham o mesmo objetivo de coligar o controle judicial de constitucionalidade com a teoria democrática e o princípio democrático. Como afirmam Cecília Caballero Lois e Gabriel Lima Marques (2012, p. 116), seu approach teórico reivindica a desconstrução semântica da supremacia judicial, mas tendo por pressuposto a afirmação da necessidade do controle de constitucionalidade como forma de garantir a própria democracia e os direitos fundamentais. O judicial review, nesse contexto, não se apesenta como uma prática irrestrita e ilimitada dos magistrados, que pode ser utilizada em toda e qualquer circunstância. A teoria destes autores parte da necessidade de criar parâmetros para sua atuação, sobretudo das Supremas Cortes, em sede de controle de constitucionalidade que estejam de acordo com a noção de democracia deliberativa ${ }^{8}$ e com a análise e interpretação do texto constitucional numa dimensão procedimental - que não nega por completo a dimensão substancial, mas prepondera em detrimento desta última.

\section{II.I Jürgen Habermas}

Jürgen Habermas em sua obra clássica "Direito e democracia: entre facticidade $e$ validade", elabora uma teoria do controle de constitucionalidade com base nos parâmetros de uma teoria discursiva (HABERMAS, 1989). Partindo da filosofia da linguagem, a teoria discursiva de Habermas é uma aposta no sujeito, na sua subjetividade e autonomia, de modo a criar os mecanismos para uma "razão comunicativa"9 que opera livremente, sem coerção. A ação comunicativa é uma forma de garantir a integração social em sociedades marcadamente plurais, na qual os interesses de diferentes grupos possam ser discutidos por meio da deliberação pública e argumentação racional que busca superar a racionalidade instrumental (HABERMAS, 1968). Para Habermas, é a partir disso que o direito se edifica com legitimidade democrática. A "razão comunicativa", nesse sentido, seria uma forma de discurso comprometida com a coesão social, o respeito mútuo, os processos deliberativos, e não orientada por uma lógica “meio-fim”, mas pela busca da argumentação racional e do entendimento mútuo ${ }^{10}$.

O agir comunicativo se inscreve no espaço da esfera pública, que não se restringe à política institucional, mas estende-se ao âmbito do "político" na forma como Chantal Mouffe

\footnotetext{
${ }^{8}$ Tanto Habermas quanto Nino partem de uma concepção de controle de constitucionalidade que posiciona em sua centralidade a perspectiva de uma democracia deliberativa.

${ }^{9}$ Habermas constrói o conceito de "razão comunicativa", que se refere à racionalidade socialmente aplicada na interação dialógica, que passa a ganhar sentido a partir do discurso. Para aprofundamentos, ver: Habermas (1989).

10 "Através do agir comunicativo, em que as pretensões de validade devem ser justificadas discursivamente pelos próprios interessados, pessoas morais, livres e iguais, chega-se a um entendimento sobre os fundamentos normativos da sociedade político-jurídica. Só mediante o debate na esfera pública, utilizando-se da razão discursiva, para Habermas, tornam-se legítimas as justificativas, que têm por objetivo o consenso e a cooperação social diante dos dissensos que caracterizam a vida em sociedade nos dias atuais" (CHAVES, 2013, p. 69).
} 
(1993, p. 1993) o define. A política deliberativa, nesse sentido, almejando a busca por consenso, se desenvolve normativamente neste contexto, confluindo para a produção do direito legítimo, num "processo destinado a solucionar problemas, o qual trabalha com saber, ao mesmo tempo em que o elabora, a fim de programar a regulação de conflitos e a persecução de fins coletivos" (HABERMAS, 1997, p. 45), da mesma forma que condiciona esta produção legislativa "a um tratamento presuntivamente racional de problemas, cujo modo de interrogação corresponde aos problemas que sempre foram elaborados de forma quase inconsciente" (HABERMAS, 1997, p. 47). Em efeito, Habermas argumenta que é o respeito ao procedimento democrático o que confere legitimidade ao direito em sentido moderno.

Dessa forma, o judiciário e a jurisdição constitucional assumem um papel restrito em sua teoria, de modo que

\begin{abstract}
A política, na perspectiva levantada pelos procedimentalistas, constitui-se como um processo de argumentação racional, e não somente de poder, direcionado para um acordo acerca de uma forma boa e justa, ou ao menos aceitável, de ordenar os aspectos da vida que se referem às relações sociais e à natureza social das pessoas, tarefas para as quais o Poder Judiciário só pode ser mobilizado por razões que lhes são trazidas segundo a relação do "direito com a lei", restringido assim sua atividade pela legalidade imposta ao funcionamento do ordenamento jurídico. É, por fim, um paradigma fundado com uma separação mais clara entre os poderes, onde a interferência de um sobre os outros não é vista como salutar (TEIXEIRA; RADKE, 2017, p. 95)
\end{abstract}

Nesse sentido, Habermas não admite em sua teoria a prática da imposição de valores por meio da jurisdição constitucional, sendo para ele "evitável e controlável os excessos por parte do Poder Judiciário, no que concerne à criação judicial de normas" (TEIXEIRA; RADKE, 2017, p. 99). Dessa forma, o papel da jurisdição constitucional em uma democracia, numa dimensão normativa, seria a de proteger os direitos fundamentais e garantir o procedimento democrático ${ }^{11}$. Para Habermas, "ao direito e à jurisdição constitucional, por consequência, competem os discursos de aplicação, não de justificação" (TEIXEIRA; RADKE, 2017, p. 100). Muito embora reconheça que a jurisdição constitucional deve atuar de forma contramajoritária $^{12}$, o autor não admite que os tribunais constitucionais possam ir além de suas atribuições e ocupem espaços que não são tradicionalmente de sua competência institucional notadamente, os espaços "políticos". A teoria procedimental de Habermas, portanto, implica no desenho institucional de um Poder Judiciário e de Cortes Constitucionais autocontidos, que não venham a exorbitar o seu espaço constitucionalmente estabelecido de jurisdição. Isto é, seu

\footnotetext{
${ }^{11}$ Para Maria Eugênia Bunchaft, Habermas partilha de um ceticismo em relação à jurisdição constitucional, na medida em que é difícil compatibilizá-la com aspectos democráticos. Nesse sentido, para Habermas o papel da jurisdição constitucional deveria ser restrito. Para aprofundamentos, ver: Bunchaft (2011).

${ }^{12}$ Para uma compreensão mais ampla, ver: Ely (2010).
} 
espaço de legislador passivo que não inova na ordem jurídica.

\section{II.II Carlos Santiago Nino}

Carlos Santiago Nino, em sua obra clássica "La Constitución de la democracia deliberativa", parte da tensão moderna existente entre o valor do constitucionalismo e da democracia. Para ele, esta tensão não deve ser tratada no sentido de excluir ou negligenciar um ou outro valor, mas deve ser lida a partir de uma possibilidade de integração dialógica ${ }^{13}$. O controle judicial de constitucionalidade está na centralidade deste debate, pelo qual se estabelece a necessidade de criar condições para que sua operação seja adequada aos valores da democracia, pelo qual sua legitimidade enquanto processo contramajoritário é garantida.

Diferentemente de Habermas, entretanto, Nino passa a reconhecer no interior de sua teoria da democracia deliberativa um grau de substantivismo mais acentuado. $\mathrm{O}$ autor desenvolve a noção de "construtivismo epistemológico" na qual política e moral não se separam. Demonstra que em John Ralws a possibilidade de acessar o conhecimento da verdade moral é possível por meio da reflexão individual, ao passado que para Habermas é através da reflexão coletiva. Assim, sua teoria pode ser categorizada como uma espécie intermediária entre estas duas perspectivas, admitindo a possibilidade de encontrar e reconhecer a verdade moral tanto na reflexão individual quanto naquela coletiva (NINO, 1997, p. 13-14).

Nino reconhece, nessa esteira, que as decisões não podem negligenciar direitos e garantias insculpidas na Constituição, na medida em que "[...] a democracia como processo de tomada de decisões insere o sujeito nas deliberações, o constitucionalismo regula este processo, estabelecendo limites, padrões e até mesmo determinações" (CHUEIRI; GODOY, 2010, p. 171). Essa possível negligência seria a negação daquilo que Nino chama de "Constitución histórica", ou seja, uma prática social fruto de uma convenção que se inscreve no texto constitucional. As decisões tomadas no âmbito da Constituição histórica devem buscar satisfazer os princípios da Constituição ideal, que são uma espécie de núcleo essencial de princípios que não podem ser negligenciados em uma discussão jurídico-politica. Portanto, Nino elabora três grandes princípios: princípio da autonomia, inviolabilidade e dignidade da pessoa (NINO, 1997, p. 161). Para Nino, “a Constituição ideal do poder está baseada em uma justificação da democracia apoiada na transformação dos interesses das pessoas através do

\footnotetext{
13 "Sin embargo, este matrimonio entre democracia y constitucionalismo no es sencillo. Sobreviven tensiones cuando la expansión de la primera conduce a un debilitamiento del segundo o, por el contrario, el fortalecimiento del ideal constitucional se convierte en un freno para el proceso democrático. Estas tensiones no son fáciles de detectar con precisión debido a la falta de certeza respecto de que es lo que hace que la democracia sea algo valioso, cual es el modelo de democracia que maximiza ese valor, y la oscuridad de la noción misma de constitucionalismo. (NINO, 1997, p. 13-14).
} 
processo de discussão participativa e da decisão majoritária", de modo que "este processo dá qualidade epistêmica à democracia sempre que supera os problemas da dispersão da soberania, da pobreza do debate político, da apatia política e da mediação perfeita" (AGUIRRE; AFFORNALLI, 2015, p. 258).

Como bem elencam Cecília Caballero de Lois e Gabriel Lima Marques, de acordo com Nino, "para que a deliberação pública tenha valor epistêmico, faz-se necessária que ela satisfaça uma série de condições que devem ser garantidas pela Constituição":

a) a participação de todos os interessados na discussão e na decisão; b) que essa
participação se desenvolva sobre uma base razoável de igualdade e sem qualquer tipo
de coerção; c) que os participantes do debate público expressem seus interesses e os
justifiquem com argumentos genuínos; d) que o grupo que aplica deliberação tenha
uma dimensão tal que maximize a probabilidade de alcançar um resultado correto; e)
que não existam minorias sistematicamente isoladas; f) que aqueles que participam
do debate não se encontrem sob a influência de emoções extraordinárias (NINO, 1997,
p. 180-192).

Nino entende que a democracia deliberativa é um valor a ser seguido em uma sociedade caracterizada por conflitos e divergências políticas e morais, no entanto ele não nega a possibilidade de juízos individuais - nos termos de John Ralws - para se chegar à resposta certa em termos morais, políticos e jurídicos. É por meio disso que Nino fundamenta a possibilidade de justificação e legitimidade da jurisdição constitucional, na medida em que este método pode funcionar como um corretor de decisões tomadas por meio da deliberação (NINO, 1997, p. 192). Nesse sentido, o fundamento acordado por Nino ao judicial review, conforme os critérios de razão prática, o controle do procedimento democrático, o resguardo da autonomia pessoal e a preservação da prática constitucional como resultado da ação coletiva, reconhece um mínimo de objetividade moral compatível com os pressupostos formais de operatividade do sistema democrático, que revaloriza e reforça a teoria (CUADROS, 2010, p. 2010).

Dessa forma, embora Nino tenha uma visão crítica em relação à jurisdição constitucional e à sua incompatibilidade com a democracia, o autor admite que o judicial review é importante e necessário em três exceções. A primeira diz respeito ao controle do procedimento democrático, ou seja, é tarefa do judicial review realizar o controle da legalidade e constitucionalidade dos atos de produção de normas jurídicas. A segunda diz respeito à garantia dos princípios da autonomia, inviolabilidade e dignidade da pessoa, o que caracteriza uma dimensão substancial de sua teoria. A terceira exceção diz respeito ao respeito da constituição entendida como uma prática social e à Constituição histórica.

Em efeito, a teoria do controle de constitucionalidade de Nino, que também pode ser caracterizada como procedimental, é compatível com a proposta também procedimental de 
Habermas por pelo menos dois pontos que são centrais ao procedimentalismo democrático. $\mathrm{O}$ primeiro diz respeito à defesa normativa da democracia deliberativa, na qual seja garantido a todo sujeito o direito de participação no debate político-institucional; e o segundo diz respeito à uma certa desconfiança da prática do controle judicial de constitucionalidade, mas ambos também admitem que ela é importante em casos específicos com o intuito de garantir os pressupostos da democracia quando violados.

Observa-se, contudo, que tanto a perspectiva de Habermas quanto a de Nino, embora sejam "procedimentais" não podem ser confundidas como "estritamente procedimentais", ou mesmo "formalistas" - como pode, em certo sentido, ser caracterizada a teoria do controle de constitucionalidade de John Hart Ely (2010), por exemplo. Em efeito, ambas adotam um grau de substancialismo que efetivamente não se assemelha ao que propõe Ronald Dworkin (1996), mas que reconhece a necessidade do controle de constitucionalidade proteger direitos fundamentais e direitos de minorias - e não meramente de "procedimentos" - como indispensáveis para o funcionamento de uma democracia. Nesse sentido, do ponto de vista da classificação teórica pode-se falar de um "procedimentalismo-integrado" de Habermas e Nino, em razão da sua preocupação com a efetividade dos direitos fundamentais como um elemento central do controle de constitucionalidade - isto é, um diálogo mais profícuo com uma determinada perspectiva substancial.

\section{Análise crítica a partir do procedimentalismo democrático no caso Raposa Serra do Sol}

As discussões teóricas relativas ao controle de constitucionalidade - modelos e limites - passaram a ganhar relevância e expressividade a partir do final da Segunda Guerra Mundial com o processo de globalização do constitucionalismo rígido (ACKERMAN, 1997; TUSHNET, 2008), que implicou na criação de instâncias judiciais nacionais e internacionais ${ }^{14}$ caracterizadas pela revisão da legislação produzida na esfera legislativa conforme o modelo pensado por Hans Kelsen (1998). No Brasil, houve previsão do controle de constitucionalidade difuso - nos moldes estadunidenses - desde a Constituição republicada de 1891 (ARANTES, 1997) ${ }^{15}$, muito embora tenha sido um instrumento pouco utilizado na história constitucional brasileira até a promulgação da Constituição de 1988. Esta última Constituição foi a primeira que previu em seu texto um controle de constitucionalidade misto, caracterizado pela integração

\footnotetext{
14 Aqui faz-se referência ao aprimoramento normativo no campo do direito internacional dos direitos humanos. Para aprofundamentos, ver: Cançado Trindade (2003).

15 Apesar da previsão constitucional ter sido em somente 1891, o mecanismo foi trazido para a ordem jurídica brasileira em 1889.
} 
do modelo difuso estadunidense e do modelo concentrado europeu ${ }^{16}$, de modo que a Corte Suprema congrega a competência constitucional de atuar em ambas as vias. Somado ao modelo sui generis de judicial review adotado no Brasil também é notável um processo de intensificação da utilização da jurisdição constitucional no país, impulsionado pela judicialização de diversas questões que até então não faziam parte da apreciação do Poder Judiciário, o que caracteriza o atual cenário de "crise" tanto do Judiciário quanto do controle de constitucionalidade no país ${ }^{17}$.

Desde o final da Segunda Guerra Mundial, pode-se afirmar também que a discussão sobre o modelo de judicial review a ser adotado gira em torno de pelo menos duas grandes categorias: os substancialistas e os procedimentalistas. Os substancialistas entendem que o papel da jurisdição constitucional seria amplo e consistiria em identificar e proteger valores fundamentais a partir da aproximação realizada entre o direito constitucional e a ética, de modo que os magistrados teriam a atribuição de atuar no campo da identificação de princípios e na sua aplicação jurisprudencial, podendo estes inclusive transcender ao disposto no texto constitucional quando se trata da necessidade de solucionar casos difíceis. O representante mais conhecido neste campo é Ronald Dworkin que entende que o direito é uma prática essencialmente hermenêutica e defende que a jurisdição constitucional não possui qualquer incompatibilidade com a democracia, podendo ser utilizado de forma indiscriminada. Do outro lado encontram-se os procedimentalistas que entendem ser dificultosa a defesa ampla e irrestrita do controle judicial de constitucionalidade, tendo em vista que esta prática pode encontrar barreiras nos pressupostos da democracia. No entanto, os procedimentalistas também não rejeitam as potencialidades do judicial review como forma de garantir a própria democracia, e por isso defendem um modelo de controle judicial de constitucionalidade limitado, racionalizado e procedimental.

Em efeito, o modelo de controle de constitucionalidade defendido pelos teóricos procedimentalistas - do procedimentalismo-integrado conforme analisado -, como é o caso de Habermas e Nino, também se edifica a partir de elementos substanciais, haja vista que não há como se falar em um modelo procedimental puro (BUNCHAFT, 2011) hodiernamente, pois o constitucionalismo contemporâneo passou a reconhecer em seus textos constitucionais dispositivos que remetem a valores que são de difícil definição por parte dos representantes do Poder Legislativo - como é o caso do princípio da dignidade da pessoa humana, por exemplo. Dessa forma, o procedimentalismo democrático de Habermas e Nino admite um grau de

\footnotetext{
16 Apesar de que a previsão para esse modelo era anterior ao texto constitucional.
}

17 Para uma visão crítica, ver: Vieira (2008). 
substancialismo, porém restrito, na atuação das Cortes na esfera do controle judicial de constitucionalidade, conforme já visto ${ }^{18}$.

Em efeito, é notável que tanto a literatura jurídica quanto a atuação dos tribunais em sede de controle de constitucionalidade no Brasil têm privilegiado uma abordagem substancialista com peculiaridades ${ }^{19}$. O alargamento da leitura substancial e pouco procedimental da Constituição de 1988, na qual se inscrevem valores e princípios, demonstra, em muitos casos, uma ausência de argumentação com base na dogmática jurídica. Dessa forma, em vez de serem tratados com base na dogmática ou nos métodos tradicionais de interpretação do texto constitucional, muitos casos - geralmente os "hard cases", como aponta Dworkin são levados à instância de discussão da filosofia moral, o que causa, em diversos casos, insegurança jurídica.

Da mesma forma, a Corte Suprema e os tribunais na sua atuação no judicial review têm recorrentemente adentrado em competências que são constitucionalmente relegadas a outros poderes, tendo atuado cada vez mais como legislador ativo (CAPELLETI, 1993) - em vez de resguardar seu espaço tradicional de legislador passivo. Isso posiciona, inevitavelmente, a questão da legitimidade democrática do Poder Judiciário na centralidade da sua atuação. O caso em questão neste trabalho - Raposa Serra do Sol - é um evidente exemplo de uma forma de ativismo judicial no qual a Corte atuou como legislador ativo, mesmo sem haver qualquer pedido juridicamente formulado na Petição Inicial. Nessa esteira, nasce o questionamento que guia esta pesquisa de se essa atuação da Corte como legislador ativo seria legítima?

As teorias do procedimentalismo democrático estabelecem implícita ou explicitamente um modelo de separação de poderes mais acentuado ${ }^{20}$, no qual a interferência política e juridicamente descabida de um poder em outro pode gerar instabilidade, podendo ser considerada uma prática constitucionalmente ilegítima. Dentre os autores procedimentalistas tratados neste trabalho, Habermas é o que mais desenvolve uma teoria do direito calcada na separação dos poderes no primeiro volume do seu clássico "Direito e democracia". De acordo com o autor, a separação dos poderes constitui um dos princípios e pilares de um Estado democrático de direito. Para Habermas, o Estado de direito tem por elemento central a lei, que é resultado de uma prática institucional e discursiva de deliberação, isto é, da soberania popular (HABERMAS, 1997, p. 212-213). O autor afirma que as "leis formam a base para pretensões

\footnotetext{
${ }^{18}$ Para uma análise e compreensão da dicotomia entre "procedimentalismo e substancialismo", ver: Cohen (1996).

19 Trata-se de uma constatação feita por Luigi Ferrajolli, conforme: Ferrajolli (2010).

${ }^{20}$ Cabe ressaltar que a teoria da separação dos poderes, criada por Montesquieu é caracterizada por um grau maior de estaticidade, ao passo que a teoria dos checks and balances, criada nos Estados Unidos, se caracteriza por um maior nível de dinamicidade. Para aprofundamentos, ver: Capelletti (1993); Mariano (2008).
} 
jurídicas individuais; estas resultam da aplicação de leis a casos singulares, seja pelos caminhos da administração, seja pelo caminho autoexecutivo" (1997, p. 215), de modo que há, portanto, em sua teoria do procedimentalismo democrático, uma separação entre a criação e fundamentação do direito e a aplicação e justificação do direito. Referida separação existe por razões pragmáticas, que inexoravelmente sugerem uma "separação entre poder legislativo e o judiciário, tão logo a configuração dogmática do direito e a "cientificização" da jurisprudência acarreta uma ampla profissionalização da prática de decisão judicial” (1997, p. 212-213). Habermas aponta que há uma distinção lógica e argumentativa entre a fundamentação e aplicação de normas, o que se reflete nas formas comunicativas de discursos de fundamentação e de aplicação, que precisam ser institucionalizados juridicamente de diferentes maneiras.

\begin{abstract}
Em discursos jurídicos de aplicação é preciso decidir qual das normas tidas como válidas, numa situação dada, e cujas características são descritas da forma mais completa possível é adequada. Esse tipo de discurso exige, de um lado, uma constelação de papeis, na qual os partidos (e, conforme o caso, autoridades políticas mediadoras) podem apresentar todos os aspectos litigiosos de um caso a um juiz, como representante imparcial da comunidade; de outro lado, uma distribuição de competências segundo a qual o tribunal tem que fundamentar seu julgamento perante uma esfera pública jurídica, em princípio ilimitada. Ao passo que nos discursos de fundamentação há apenas participantes. De outro lado, a fim de impor suas decisões - e a execução do direito - a justiça apela para os meios de repressão do aparelho do Estado, passando a dispor, ela mesma, de um poder administrativa. Por essa razão, a justiça precisa ser separada da legislação e impedida de uma autoprogramação (HABERMAS, 1997, p. 215-216).
\end{abstract}

Carlos Nino também parte da noção de separação de poderes para construir sua teoria da democracia e do controle de constitucionalidade. De acordo com Leopoldo Lama Levya (2011, p. 251), quando Nino aponta a relevância da constituição histórica ele apela para seu caráter convencional-limitativo, "según la cual la operatividad de una democracia depende en gran medida de su arraigo en un orden constitucional que garantice la separación de poderes y lo respeto por los derechos fundamentales". Tomando isso em consideração, constata-se que é considerado ilegítimo para os autores do procedimentalismo-integrado abordados neste trabalho uma atuação ativista da Corte no campo do judicial review no sentido de produzir normas, ou seja, de atuar como legislador ativo. Em efeito, não existem elementos teóricos e/ou normativos que sustentem uma prática como essas para esses autores.

No caso Raposa/Serra do Sol existe ainda uma agravante na atuação do Supremo Tribunal Federal como legislador ativo no que tange ao conteúdo que foi inserido nas 19 condicionantes e também na questionada tese do "marco temporal". Este conteúdo é claramente restritivo aos direitos constitucionais de povos indígenas. Houve referências à inconstitucionalidade e inconvencionalidade de pelo menos três comandos contrários ao que 
está estabelecido na Convenção 169 da OIT, além de critérios - como é o caso do marco temporal - que é uma interpretação restritiva aos direitos constitucionalmente previstos aos povos indígenas no artigo 231 que reconhece aos povos indígenas os direitos originários sobre as terras que tradicionalmente ocupam, competindo à União demarcá-las, proteger e fazer respeitar todos os seus bens.

Em efeito, há que se ressaltar que não há legitimidade na atuação política do Supremo Tribunal Federal com o intuito de restringir os direitos constitucionalmente previstos de uma minoria étnica que encontra ameaças cotidianas à aplicação e efetivação de seus direitos e que pouco encontra espaço de participação nas instâncias institucionais da política. A atuação da Corte, de acordo com o procedimentalismo democrático de Habermas e Nino, deve desenvolver-se a partir da perspectiva contramajoritária. Nesse sentido, uma interpretação restritiva a direitos de minorias étnicas seria o exato contrário de uma atuação contramajoritária, pondo em xeque a legitimidade da Corte. Desse modo, não há que se falar em legitimidade quando a atuação da corte se desenvolve na linha da negação de direitos, sobretudo aos direitos de minorias étnicas, por meio de interpretações restritivas.

\section{Considerações finais}

O caso Raposa Serra do Sol é um interessante e oportuno caso para a reflexão sobre o papel da jurisdição constitucional no atual contexto político e jurídico brasileiro.

Desde o vicejar do século XXI, a Suprema Corte - e o Judiciário de modo geral - vem assumindo protagonismo político no país, sobretudo em razão da crescente judicialização da política que, para muitos teóricos, trata-se de um fenômeno irreversível ${ }^{21}$. Para parcela considerável da literatura jurídica contemporânea, o agigantamento das atribuições do Poder Judiciário e a consequente atuação deste último como legislador ativo seria resultado e característica "normal" do atual estágio do constitucionalismo contemporâneo no qual os magistrados adquirem maior protagonismo no cenário jurídico e político.

Entretanto, a atuação da Suprema Corte como legislador ativo é marcada pela ausência de legitimidade quando não há expressa previsão para tanto. O Supremo Tribunal Federal - e o Judiciário - não constitui uma instância ou poder representativo, de modo que uma eventual produção legislativa nesta esfera seria de difícil defesa considerando apenas este aspecto isolado. Para os teóricos do procedimentalismo democrático analisados, o que confere legitimidade a uma lei é o respeito ao seu procedimento e o processo de deliberação pública, de

${ }^{21}$ Para aprofundamentos, ver: Hirschl (2012, pp. 63-96). 
modo que o controle de constitucionalidade teria legitimidade para atuar na garantia do procedimento democrático, quando viola-se o direito de participação de todos os interessados no processo deliberativo, sobretudo minorias, e quando há claro desrespeito aos direitos fundamentais. Para além disso, a legitimidade da Suprema Corte pode ser questionada.

Nesse sentido, as teorias do procedimentalismo democrático de Habermas e Nino fornecem um arsenal teórico para se repensar as práticas judiciárias no atual contexto brasileiro, caracterizado pela valorização - muitas vezes irrefletida e desassociada de suas consequências - de abordagens substancialistas e daquelas que legitimam o ativismo judicial como elemento "natural" da jurisdição constitucional ou comum. É fato que a cada vez maior atuação do STF como legislador ativo se deve à ausência de parâmetros para sua atuação legítima em casos que envolvem, por exemplo, os direitos de minorias étnicas - como é o caso dos povos indígenas. O procedimentalismo democrático de Habermas e Nino advogam pela garantia da legitimidade jurídica e política por meio da separação dos poderes, apontando para a ilegitimidade da usurpação de poderes nos contextos em que não existe previsão constitucional para tanto.

\section{Referências}

AB'SÁBER, Aziz. A região da reserva Raposa Serra do Sol: prévias para seu entendimento. Estudos Avançados, v. 23, n. 65, 2009.

ACKERMAN, Bruce. The Rise of World Constitutionalism. Virginia Law Review 83, $\mathrm{n}^{\circ} .4$, pp. 771-797, 1997.

ADVOCACIA-GERAL DA UNIÃO. Parecer n. 001/2017/GAB/CGU/AGU, Interessado: Casa Civil da Presidência da República. Diário Oficial da União, 19 jul 2017.

AGUIRRE, Lissandra; AFFORNALLI, Marcos. O controle de constitucionalidade de leis: entre Carlos Santiago Nino e Roberto Gargarella. In: LIMA, Martonio Mant'Alverne Barreiro; RAMOS, Paulo Roberto Barbosa. Florianópolis : CONPEDI, 2015.

ARANTES, Rogério Bastos. Judiciário e Política no Brasil. São Paulo : Idesp, 1997.

BUNCHAFT, Maria Eugênia. Constitucionalismo Democrático versus Minimalismo. Direito, Estado e Sociedade, v. 38, p. 1-20, 2011.

CANÇADO TRINDADE, Antônio Augusto. Tratado de Direito Internacional dos Direitos Humanos. Vol. I. Porto Alegre : Sérgio Antonio Fabris Editor, 2003.

CHAVES, Ronado Santana. A teoria procedimental de Habermas: a superação do conflito entre autonomia privada e autonomia pública. Dissertação de Mestrado em Filosofia. Universidade Federal de Santa Catarina, 2013. 
CHUEIRI, Vera Karam de; GODOY, Miguel Gualano. Constitucionalismo e Democracia: soberania e poder constituinte. São Paulo: Revista Direito GV, São Paulo, n. 11, jan.-jun. 2010.

COHEN, Joshua. Procedure and substance in deliberative democracy. In: BENHABIB, Seyla. Democracy and difference: contesting the boundaries of political. Princeton : Princeton University Press, 1996.

CUADROS, Oscar. Fundamento del control de constitucionalidad en la teoría del derecho de Carlos S. Nino. Mexico : Biblioteca Virtual de UNAM, 2010.

CUNHA, Manuela Carneiro da. Os direitos do índio: ensaios e documentos. São Paulo : Imprenta, 1987.

CUNHA, Manuela Carneiro da; BARBOSA, Samuel (Orgs.). Direitos de povos indígenas em disputa. São Paulo : Editora UNESP, 2018

DWORKIN, Ronald. Freedom's law: the moral Reading of the American Constitution. Harvard : Harvard University Press, 1996.

ELY, John Hart. Democracy and distrust: a theory of Judicial Review. Cambridge : Harvard Press University, 2010.

FERRAJOLLI, Luigi. Constitucionalismo garantista e neoconstitucionalismo. Anais do IX Simpósio de Direito Constitucional. Academia Brasileira de Direito Constitucional, Curitiba, 2010.

HABERMAS, Jürgen. Direito e Democracia: entre facticidade e validade. Volume I. Rio de Janeiro: Tempo Brasileiro, 1997.

HABERMAS, Jürgen. Direito e Democracia: entre facticidade e validade. Volume II. Rio de Janeiro: Tempo Brasileiro, 1997.

HABERMAS, Jürgen. Consciência Moral e Agir Comunicativo. Rio de Janeiro: Tempo Brasileiro, 1989.

HABERMAS, Jürgen. Técnica e ciência como ideologia. Lisboa : Edições 70, 1968.

HIRSCHL, Ran. A judicialização da megapolítica e o surgimento dos tribunais políticos. In. MOREIRA, Luiz (Org.). Judicialização da Política. São Paulo : Editorial 22, 2012.

JÚNIOR, João Mendes. Os indígenas do Brazil: seus direitos individuaes e políticos. São Paulo : Typ. Hennies Irmãos, 1912.

KAYSER, Hartmut-Emanuel. Os direitos dos povos indígenas do Brasil: desenvolvimento histórico e estágio atual. Porto Alegre : Sérgio Antonio Fabris, 2010.

KELSEN, Hans. Teoria pura do direito. São Paulo : Martins Fontes, 1998. 
LOIS, Cecília Caballero; MARQUES, Gabriel Lima. A Desconstrução Semântica da Supremacia Judicial e a Necessária Afirmação do Judicial Review: uma análise a partir da democracia deliberativa de Habermas e Nino. Sequencia, v. 34, p. 113-136, 2013.

MIRAS, Julia Trujillo (et. al.). Makunaima Grita! Terra Indígena Raposa Serra do Sol e os direitos constitucionais no Brasil. Rio de Janeiro : Beco do Azougue, 2009.

MOTA, Carolina. A demarcação da terra indígena Raposa Serra do Sol: processo administrativo e conflitos judiciais. In: MIRAS, Julia Trujillo (Org.). Makunaíma Grita! Terra Indígena Raposa Serra do Sol e os direitos constitucionais no Brasil. Rio de Janeiro : Beco do Azougue, 2009.

MOUFFE, Chantal. O regresso do político. Gradiva: Lisboa, 1993.

NINO, Carlos Santiago. La constitución de la democracia deliberativa. Barcelona: Gedisa, 1997.

SUPREMO TRIBUNAL FEDERAL. Petição 3.388/RR, julgamento 19/03/2009, Relator: Min. Carlos Britto, Órgão julgador: Tribunal Pleno.

TEIXEIRA, Anderson; RADKE, Rafael. Habermas e a tentativa procedimental de superação da discricionariedade judicial. Revista Brasileira de Estudos Políticos, Belo Horizonte, n. 115, pp. 81-108, jul./dez. 2017.

TUSHNET, Mark. The inevitable globalization of constitutional law. Harvard Public Law Working Paper, Hague Institute for the Internationalization of Law, n. 09-06, 2008.

VIEIRA, Oscar Vilhena. Supremocracia. Revista Direito GV, v. 4, 2008.

VILLARES, Luiz Fernando. Direito e Povos Indígenas. Curitiba : Juruá, 2009.

YAMADA, Erica Magami; VILLARES, Luiz Fernando. Julgamento da terra indígena Raposa Serra do Sol: todo dia era dia de índio. Revista Direito da FGV São Paulo, v. 6, jan-jul 2010. 